\title{
CLINICAL RELEVANCE OF ERYTHROCYTE FERRITIN IN MICROCYTIC ANEMIAS
}

${ }^{1}$ Jose M. Vagace MD, PhD, ${ }^{2}$ Antonio Peças MD; ${ }^{1}$ Jorge Groiss MD PhD, ${ }^{2}$ Celeste Bento MD PhD;

${ }^{2}$ Maria Leticia Ribeiro MD PhD, ${ }^{3}$ Guillermo Gervasini, PhD

${ }^{1}$ Service of Hematology, Infanta Cristina Hospital; ${ }^{2}$ Service of Hematology, Centro Hospitalar e Universitário de Coimbra, Coimbra, Portugal; ${ }^{3}$ Department of Surgical \& Medical Therapeutics, University of Extremadura, Badajoz, Spain

Correspondence should be addressed to:

Jose Manuel Vagace Valero

Infanta Cristina Hospital

Av.Elvas s/n 06071 Badajoz

Tel: +34924215335

Email: jvagacev@gmail.com 


\section{ABSTRACT}

Background: Erythrocyte ferritin (EF) reflects the balance between iron supply and its utilization for hemoglobin synthesis. This balance is altered in microcytosis. We aimed to evaluate the diagnostic value of both EF and the ratio (FRR) plasma ferritin (PF)/EF in these disorders.

Methods: A total of 231 subjects participated in the study. Samples from 93 adult patients with different causes of microcytosis, 57 healthy subjects and 81 full term newborns were analyzed to determine EF and PF concentrations and other hematological parameters.

Results: In patients with iron deficiency, and in contrast to PF, EF decreased only in the presence of anemia and in direct correlation with the degree of microcytosis (Pearson's $p<0.001)$. EF values for thalassemia patients were higher than those observed in controls $(p<$ 10e-5), whilst PF concentrations were similar between these groups. This EF increase was more marked in the delta-beta thalassemia group $(p<0.05)$. Finally, FRR was much higher in patients with anemia of inflammation than in those with thalassemia $(p<10 e-5)$, thus helping to discriminate between these disorders.

Conclusions: EF and FRR are tools that may be useful in the diagnosis of the main causes of microcytosis.

Keywords: Erythrocyte ferritin, anemia, microcytosis, thalassemia, iron defficiency 


\section{INTRODUCTION}

Microcytic anemias are mainly caused by two mechanisms, namely iron deficiency and subsequent decrease in the synthesis of the heme group or decreased synthesis of globin chains (e.g. thalassemias). Iron deficiency and its most severe manifestation, iron-deficiency anemia, are public health problems worldwide [1]. However, iron deficiency constitutes a broad concept, both in terms of the number of affected subjects and of the deleterious effects that this deficiency has on the patient's health [2] $]$. On the other hand, thalassemias are a group of genetic disorders of hemoglobin $(\mathrm{Hb})$ synthesis characterized by a reduced or absent production of one or more globin chains. Thalassemia syndromes constitute one of the most frequent genetic defects in humans. Heterozygous forms may be silent or present with microcytosis, whilst homozygous forms cause progressively serious conditions, from intermediate to major syndromes [ [3]. The anemia resulting from either acute or chronic inflammatory processes has been traditionally, but incorrectly, named Anemias of Chronic Disease (ACD). This $A C D$, anemia of inflammation would be the correct term, are coupled with abnormalities in iron metabolism which result in microcytosis in $25-30 \%$ of cases [4].

After evaluation of the hemogram, the study of microcytosis should begin with the assessment of iron deposits. For this, one of the most valuable parameters currently available is the determination of plasma ferritin (PF) concentrations. However, whilst PF levels below 20 $\mathrm{ng} / \mathrm{mL}$ is a sign of iron deficiency [ㄷ], normal or even elevated concentrations cannot completely rule out the disorder. This is because PF is a positive acute-phase protein, i.e., numerous circumstances such as inflammation, hepatopathies or malignancies, may result in increased ferritin plasma levels with no relation to iron deposits [6-8]. In contrast, erythrocyte ferritin (EF), which also correlates with iron stores [9] , is not an acute-phase reactant, which 
makes it an advantageous parameter to evaluate iron functional availability in the aforementioned circumstances $[\underline{2}, \underline{9}, \underline{10}]$.

In the present work, we have aimed to evaluate the utility of both EF and the ratio PF/EF for the diagnosis of microcytosis in the hospital setting, and to discuss the significance of these parameters as an approach to understanding iron metabolism in several pathologies that present with microcytosis. A secondary goal was to analyze a control population of adults and newborns to investigate putative differences in EF levels that may reflect a different iron metabolism in these two groups.

\section{PATIENTS AND METHODSe}

The study included a total of 231 subjects divided into three groups. A first group consisted of 93 consecutive adult patients (36 males) with microcytosis who were diagnosed at the Infanta Cristina University Hospital (Badajoz, Spain) according to the nomogram depicted in Figure 1. The number of patients with the different pathologies is shown in Table 1. The second study group included 57 control subjects (28 males), recruited among the hospital staff, who showed a normal hemogram with no iron deficiency, thalassemia or hemoglobinopathies. Finally, umbilical cord blood samples were collected from 81 full-term newborns at the Materno Infantil Hospital (Badajoz, Spain) in EDTA tubes immediately after birth by puncturing of the umbilical vein.

Plasma was separated from the cells in all the samples and the erythrocytes were concentrated by centrifugation at $1400 \mathrm{~g}$ for ten minutes followed by resuspension in saline. An aliquot of this erythrocyte suspension was subjected to cell count in an automated counter (Beckman Coulter ${ }^{\circledR} \mathrm{Hmx}$, Beckman Coulter Inc., Galway, Ireland). Ferritin levels were 
quantified in plasma or erythrocyte concentrates by a solid-phase chemiluminiscence enzyme immunoassay (Immulite 2000, Siemens Healthcare Diagnostics, Malvern, PA, USA), which uses basic anti-ferritin antibodies. Knowing the concentration of the erythrocyte concentrate, EF concentration was calculated and expressed in attograms (ag) per cell (1 ag $=10 \mathrm{e}-18 \mathrm{~g})$.

Patients with low plasma ferritin concentrations $(<20 \mathrm{ng} / \mathrm{mL})$ with no presence of anemia were classified as latent iron deficiency, regardless of corpuscular parameters. In addition, if the patient had a family history of thalassemia, $\mathrm{Hb}-\mathrm{A}_{2}$ was determined regardless of ferritin levels (eight cases of thalassemia associated with iron deficiency were thus diagnosed). Atypical microcytoses were not included in this work because the genetic tests for alphathalassemia were not completed at the time of the study. All patients included in the anemia of inflammation group also presented with elevated acute-phase reactants, e.g. speed of globular sedimentation or C-reactive protein.

All subjects involved (or their parents in the case of the newborns) gave written consent for their participation. The study was approved by the Research Ethics Board of the University Hospital Infanta Cristina (Badajoz, Spain) and was conducted in accordance to the Declaration of Helsinki and subsequent revisions.

\subsection{Statistical analyses}

Statistical analyses were performed using SPSS software version 15.0 for windows (SPSS Chicago, IL). Results are expressed as mean \pm SD. Differences of quantitative variables between groups were assessed by nonparametric tests or by Student's $t$ and ANOVA tests after log transformation of the data. Correlations between measured parameters were calculated by 
the Pearson's correlation coefficient. Statistical significance was set at a $p$-value $<0.05$ in all instances.

\section{RESULTS \& DISCUSSION}

Clinical characteristics of both patients and controls are described in Table 1. Different pathologies were identified in the 93 patients with microcytosis, namely iron deficiency (with and without anemia), beta and delta-beta minor thalassemia and anemia of inflammation. It is known that females usually show higher levels of PF than men, therefore stratification by sex was carried out before performing statistical associations. Differences were not attributable to gender in any instance (data not shown). EF values for the control population (Table 1) were comparable to those previously reported $[\underline{11}, \underline{12}]$.

\subsection{Erythrocyte ferritin in iron deficiency}

The iron deficiency threshold was set at $7 \mathrm{ag} / \mathrm{cell}$ based on data from previous study by our group [13]. EF mean concentrations in the iron deficiency group were significantly lower than those measured in control subjects $(5.76 \pm 4.29$ vs. $9.92 \pm 5.37 \mathrm{ag} /$ cell, $\mathrm{p}<0.0001)$.

In order to determine how early the EF decreases in the development of iron deficiency anemia, we compared EF levels between patients with iron deficiency anemia (34 cases) and those with latent iron deficiency (12 cases; Figure2). Panel A shows that EF concentrations in patients with asymptomatic iron deficiency $(8.74 \pm 4.68 \mathrm{ag} / \mathrm{cell})$ were not significantly different from those observed in controls $(p>0.05)$. In contrast, PF levels (Panel B) for the patients with latent iron deficiency were much lower than in control subjects $(p<10 e-5)$. This suggests that the EF decreases at a late stage in the development of iron deficiency. Thus, it seems that the erythroblast still receives and adequate iron supply after the body deposits have been used up. 
The decrease in EF levels reflects a shortage of iron supply coincidental with the onset of clinical manifestations typical of consolidated iron deficiency, i.e. anemia and microcytosis.

Interestingly, when the correlation between mean corpuscular volume (MCV) and EF and PF values was analyzed in the iron deficiency group, EF showed the best correlation with the degree of microcytosis (Pearson coefficients $=0.52$ vs. $0.37 ; p$ values were 0.0002 and 0.01 for EF and EP, respectively; Figure 3). These data suggest that EF is more important in terms of determining the hemoglobinization of the erythroblast.

\subsection{Erythrocyte ferritin in Thalassemias}

EF values for thalassemia patients were almost nine times higher than those observed in controls (86.2 \pm 57.1 vs. $9.9 \pm 5.4$ ag/cell; $p<10$ e-5; Table 1$)$. In contrast, PF concentrations were similar between these two groups $(p>0.05)$. As Piperno et al. suggest [14], this would indicate that the deficiency in the synthesis of globin is the main factor contributing to the accumulation of EF in these individuals, because the free globin chains precipitate resulting in the release of intracellular iron leading to an increase of EF [1ㄷ].

The comparison of EF values between patients with Beta $(n=25)$ and Delta-Beta Thalassemia $(n=11)$, showed significantly higher concentrations in the second group $(71.66 \pm$ 46.80 vs. $124.10 \pm 64.03 \mathrm{ag} / \mathrm{cell} ; \mathrm{p}=0.044$; Figure 4). However, PF levels were similar (82.20 \pm 80.33 vs. $89.14 \pm 73.42, p>0.05$; Figure 4 ) and therefore the difference in EF cannot be explained by differences in iron deposits. Delta-Beta thalassemia is characterized by a heterogeneous increased of $\mathrm{HbF}$ levels. We hypothesize that (i) the greater instability of $\mathrm{HbF}$ leads to increased precipitation of iron inside the erythroblast or (ii) that higher levels of free 2,3-diphosphoglycerate (DPG) induce a certain degree of diserithropoiesis, which is a known cause of EF increase [12]. 
We could identify eight Thalassemia patients with associated iron deficiency (PF $<20$ $\mathrm{ng} / \mathrm{mL})$, who also displayed much higher EF levels $(71.83 \pm 37.72)$ than control subjects did $(\mathrm{p}<$ 10e-5). Therefore, it seems that this parameter could be helpful in the diagnosis of Thalassemia with coupled iron deficiency, as it is known that $\mathrm{HbA} 2$ may be normal if iron deficiency is present [2].

\subsection{Ferritin ratio}

Next, we evaluated the utility of the ferritin ratio (FRR) $[P F(n g / m L) / E F(a g / c e l l)]$ for the diagnosis of microcytosis. In normal controls, the mean ratio was $8.17 \pm 6.33$, showing minimal overlap with the distribution observed in the patients with microcytosis. Figure 5 shows that there were significant differences $(p<0.05)$ in the ratio values between all groups except for the comparison of iron deficiency with thalassemia (FRR $=1.61 \pm 2.16$ vs. $1.54 \pm 2.13$, respectively). Paradoxically, the reasons for the low FRR observed in the iron deficiency and thalassemia groups are opposite. FRR was low in iron deficiency because the iron deposits (represented by lower PF concentrations) become depleted before the levels inside the erythroblast (EF) are affected. In contrast, the low FRR value in the Thalassemia group results from the increase of EF produced by the accumulation of iron in the erythroblast that fails to bind the globin, which is not adequately synthesized. The evaluation of FRR in anemia of inflammation is discussed below.

\subsection{Erythrocyte ferritin in anemia of inflammation}

Mean EF concentration in this group was $10.48 \pm 6.84 \mathrm{ag} / \mathrm{cell}$, similar to that observed in control subjects (Table 1). Conversely, PF values $(274.82 \pm 332.95 \mathrm{ng} / \mathrm{mL}$ ) displayed great variability and were significantly higher than those found in the control group $(p<0.001$; Table 1). Anemia of inflammation is the pathology where the use of the FRR is probably more 
helpful. The ratio is able to discriminate between thalassemia and anemia of inflammation, because in the latter disorder FRR appears distinctly elevated ( $1.54 \pm 2.13$ vs. $26.95 \pm 25.65, p$ $<$ 10e-5; Figure 5), reflecting the blockade of iron deposits in the mononuclear phagocyte system.

The anemia of inflammation is currently considered a manifestation of the effect of inflammatory mediators [4]]. Different mechanisms are involved in its pathophysiology, although the overproduction of hepcidin induced by interleukin- 6 seems to play a prominent role [16]. Hepcidin binds to ferroportin (an iron exporter expressed in enterocytes and macrophages), triggering its internalization and therefore decreasing iron efflux from these locations into plasma. Persistent hepcidin elevation restricts iron availability for erythropoiesis [17]. However, EF levels in these patients with anemia of inflammation were comparable to those of controls (Table 1), which suggests the existence of other factors determining EF concentrations, such as the relative deficiency of erythropoietin [4]. In this regard, we have previously reported inverse correlation between EF and erythropoietin levels [18].

Moreover, in contrast to the acute-phase reactant PF, EF is independent of the inflammatory state of the patient and therefore may be useful to detect iron deficiency associated to this disorder. EF levels lower than $7 \mathrm{ag} /$ cell may justify a therapeutic test with iron [13] .

\section{Erythrocyte ferritin in newborns}

The importance of iron in the development of the fetus and the newborn prompted us to investigate the role of EF vs. PF in this population. Eighty-one (41 males and 40 females) healthy Spanish full-term newborns ( $39.95 \pm 1.08$ gestation weeks) with a mean weight of 3.27 $\pm 0.45 \mathrm{~kg}$ were studied. PF mean concentration in this group $(193.04 \pm 97.40 \mathrm{ng} / \mathrm{ml})$ was similar 
to that reported in previous studies in newborns $[\underline{19}, \underline{20}]$. However, we observed in our series a mean EF value of $548.4 \pm 32.5 \mathrm{ag} /$ cell, which was almost sixty times higher than that obtained in the control group. These high values have also been observed by the other study that has analyzed this parameter in newborns, although the reported differences were not so marked [21]. The lower gestational age of the participants in this last study may explain this discrepancy with our results, as red cell ferritin increases through pregnancy [21].

These observed high EF values stress the importance of erythrocyte iron deposits in fetal hematopoiesis. An excess of iron uptake into the erythroblast in case of transferrin saturation or a decrease in iron consumption for globin synthesis could be behind this finding [12]. It should be remarked that the blood in the fetus contains mainly $\mathrm{HbF}$, this $\mathrm{Hb}$ could also be related to the EF increase for the same reasons we previously described in the section dealing with Delta-Beta Thalassemia. In any case, the precise molecular mechanisms underlying the exceptionally high EF concentrations in newborns are still unknown.

\section{CONCLUSIONS}

The determination of red cell ferritin is currently not commonly carried out, mainly because is time-consuming and because it is not viable in transfused patients. However, this parameter may provide the clinician with relevant data for the diagnosis of microcytosis. For instance, EF values deplete with the onset of a clinically significant iron deficiency. In addition, this parameter is highly elevated in Thalassemia, especially in Delta-Beta thalassemia.

Moreover, in the anemia of inflammation, EF does not behave as an acute-phase reactant and therefore the ratio between plasma and erythrocyte ferritin is greater in patients with this disorder than in any other microcytosis. Finally, we observed that EF is exceptionally elevated 
in umbilical cord blood from full-term newborns, although the precise mechanisms underlying this finding are yet to be clearly established.

\section{CONFLICT OF INTERESTS}

The authors declare that they have no conflicts of interests.

\section{ACKNOWLEDGEMENTS}

This work has been supported in part by grant GR10022 from Junta de Extremadura, Consejería de Economía, Comercio e Innovación, Merida (Spain). We are also greatful to Dr Fernando Ataulfo Gonzalez for his valuable critical imput. 


\section{REFERENCES}

[1] WHO, Iron deficiency anemia: assessment, prevention and control. A guide for programme managers. In: Organization WH, editor. Geneva, 2001.

[2] Beutler E, Disorders of Iron Metabolism. In: Kaushansky K, Lichtman M, Beutler E, Kipps T, Prchal J, Seligsohn U, editors. Williams Hematology. New York: McGraw-Hill, 2010. [3] Weatherall DJ, The Thalassemias. Disorders of globin synthesis. In: Kaushansky K, Lichtman M, Beutler E, Kipps T, Prchal J, Seligsohn U, editors. Williams Hematology. New York: McGraw-Hill, 2010: 675-707.

[4] Nemeth E, Ganz T. Anemia of inflammation. Hematology/oncology clinics of North America 2014; 28:671-681, vi.

[5] Harju E, Pakarinen A, Larmi T. A comparison between serum ferritin concentration and the amount of bone marrow stainable iron. Scandinavian journal of clinical and laboratory investigation 1984; 44:555-556.

[6] Tomkins A. Assessing micronutrient status in the presence of inflammation. The Journal of nutrition 2003; 133:1649S-1655S.

[7] Hoffbrand AV, Hershko C, Camaschella C, Iron metabolism, iron deficiency and disorders fo the haem synthesis. In: Hoffbrand AV, Catovsky D, Tuddenham EGD, Green AR, editors. Postgraduate haematology. Oxford: Wiley-Blackwell, 2010: 26-45.

[8] Brittenham GM, Disorders of Iron Homeostasis: Iron Deficiency and Overload. In: Hoffman R, Benz E, Silberstein L, Heslop H, Weitz J, Anastasi J, editors. Hematology: basic principles and practice. Philadelphia, PA: Saunders Elsevier, 2012.

[9] Balaban EP, Sheehan RG, Demian SE, Cox JV, Frenkel EP. Evaluation of bone marrow iron stores in anemia associated with chronic disease: a comparative study of serum and red cell ferritin. American journal of hematology 1993; 42:177-181. 
[10] Galan P, Sangare N, Preziosi P, Roudier M, Hercberg S. Is basic red cell ferritin a more specific indicator than serum ferritin in the assessment of iron stores in the elderly? Clinica chimica acta; international journal of clinical chemistry 1990; 189:159-162.

[11] Brunati C, Piperno A, Guastoni C, et al. Erythrocyte ferritin in patients on chronic hemodialysis treatment. Nephron 1990; 54:219-223.

[12] Cazzola M, Dezza L, Bergamaschi G, et al. Biologic and clinical significance of red cell ferritin. Blood 1983; 62:1078-1087.

[13] Caravaca F, Vagace JM, Aparicio A, et al. Assessment of iron status by erythrocyte ferritin in uremic patients with or without recombinant human erythropoietin therapy. American journal of kidney diseases : the official journal of the National Kidney Foundation $1992 ; 20: 249-254$.

[14] Piperno A, Sampietro M, Taddei MT, Fiorelli G. Factors affecting erythrocyte ferritin content in thalassaemia intermedia. British journal of haematology 1984; 56:173-174.

[15] Winter WE, Bazydlo LA, Harris NS. The molecular biology of human iron metabolism. Laboratory medicine $2014 ;$ 45:92-102.

[16] Rodriguez R, Jung CL, Gabayan V, et al. Hepcidin induction by pathogens and pathogenderived molecules is strongly dependent on interleukin-6. Infection and immunity 2014; $82: 745-752$.

[17] Ganz T, Nemeth E. Hepcidin and iron homeostasis. Biochimica et biophysica acta 2012; 1823:1434-1443.

[18] Vagace JM, Brull JM. Influencia de las distintas prácticas deportivas sobre los depósitos de hierro. Sangre 1994; 39 (Suppl 2):74.

[19] Siddappa AM, Rao R, Long JD, Widness JA, Georgieff MK. The assessment of newborn iron stores at birth: a review of the literature and standards for ferritin concentrations. Neonatology 2007; 92:73-82. 
[20] Siimes AS, Siimes MA. Changes in the concentration of ferritin in the serum during fetal life in singletons and twins. Early Hum Dev 1986; 13:47-52.

[21] Carpani G, Marini F, Ghisoni L, Buscaglia M, Sinigaglia E, Moroni G. Red cell and plasma ferritin in a group of normal fetuses at different ages of gestation. European journal of haematology 1992; 49:260-262. 


\section{FIGURE LEGENDS}

Figure 1. Nomogram for the diagnosis of the different microcytosis considered. MCV, mean corpuscular volume; $\mathrm{Hb}$, hemoglobin. ${ }^{\mathrm{a}}$ The term atypical microcytosis includes those cases with putative alpha-thalassemia minor.

Figure 2. Erythrocyte (A) and plasma (B) ferritin values in control subjects and individuals with iron deficiency (ID) with and without anemia. ${ }^{*} p<10 \mathrm{e}-5$ vs. controls.

Figure 3. Correlation between mean corpuscular volume (MCV) and erythrocyte (A) and plasma (B) ferritin values in patients with iron deficiency.

Figure 4. Comparison of erythrocyte (A) and plasma (B) ferritin values between patients with Beta and Delta-Beta Thalassemia. ${ }^{*} p<0.05$ vs. mean value in the Beta Thalassemia group.

Figure 5. Ferritin ratio (FRR) in all study groups. 


\section{TABLES}

Table 1. Clinical characteristics of patients and control subjects.

\begin{tabular}{lccccc}
\hline & Controls & Ferropenia & Thalassemia & $\begin{array}{c}\text { Anemia of } \\
\text { inflammation }\end{array}$ & Newborns \\
\hline Males & 28 & 15 & 15 & 6 & 41 \\
Females & 29 & 31 & 21 & 5 & 40 \\
Hb & $14.9 \pm 1.1$ & $10.9 \pm 1.9$ & $12.0 \pm 1.3$ & $10.8 \pm 1.6$ & $15.8 \pm 1.6$ \\
MCV & $88 \pm 4$ & $73 \pm 9$ & $65 \pm 4$ & $77 \pm 3$ & $109 \pm 6$ \\
RDW & $13 \pm 1$ & $18 \pm 5$ & $17 \pm 3$ & $17 \pm 2$ & - \\
PF (ng/ml) & $76.2 \pm 46.7$ & ${ }^{* * *} 7.6 \pm 7.5$ & $83.4 \pm 76.1$ & ${ }^{*} 274.8 \pm 332.9$ & $193.0 \pm 97.4$ \\
EF (ag/cell) & $9.9 \pm 5.4$ & ${ }^{* *} 5.8 \pm 4.3$ & $* * * 86.2 \pm 57.1$ & $10.6 \pm 6.4$ & ${ }^{* * *} 580.2 \pm 295.1$ \\
\hline
\end{tabular}

${ }^{*} \mathrm{p}<0.001 ;{ }^{* *} \mathrm{p}<0.0001 ;{ }^{* * *} \mathrm{p}<10 \mathrm{e}-5$ (all comparisons vs. control group).

$\mathrm{Hb}$, hemoglobin; MCV, mean corpuscular volume; RDW, red cell distribution width; PF, plasma ferritin; $E F$, erythrocyte ferritin

${ }^{\mathrm{a}} \mathrm{RDW}$ was not measured in the newborns 


\section{Figure 1}

$$
\mathrm{MCV}<80 \mathrm{fl}
$$

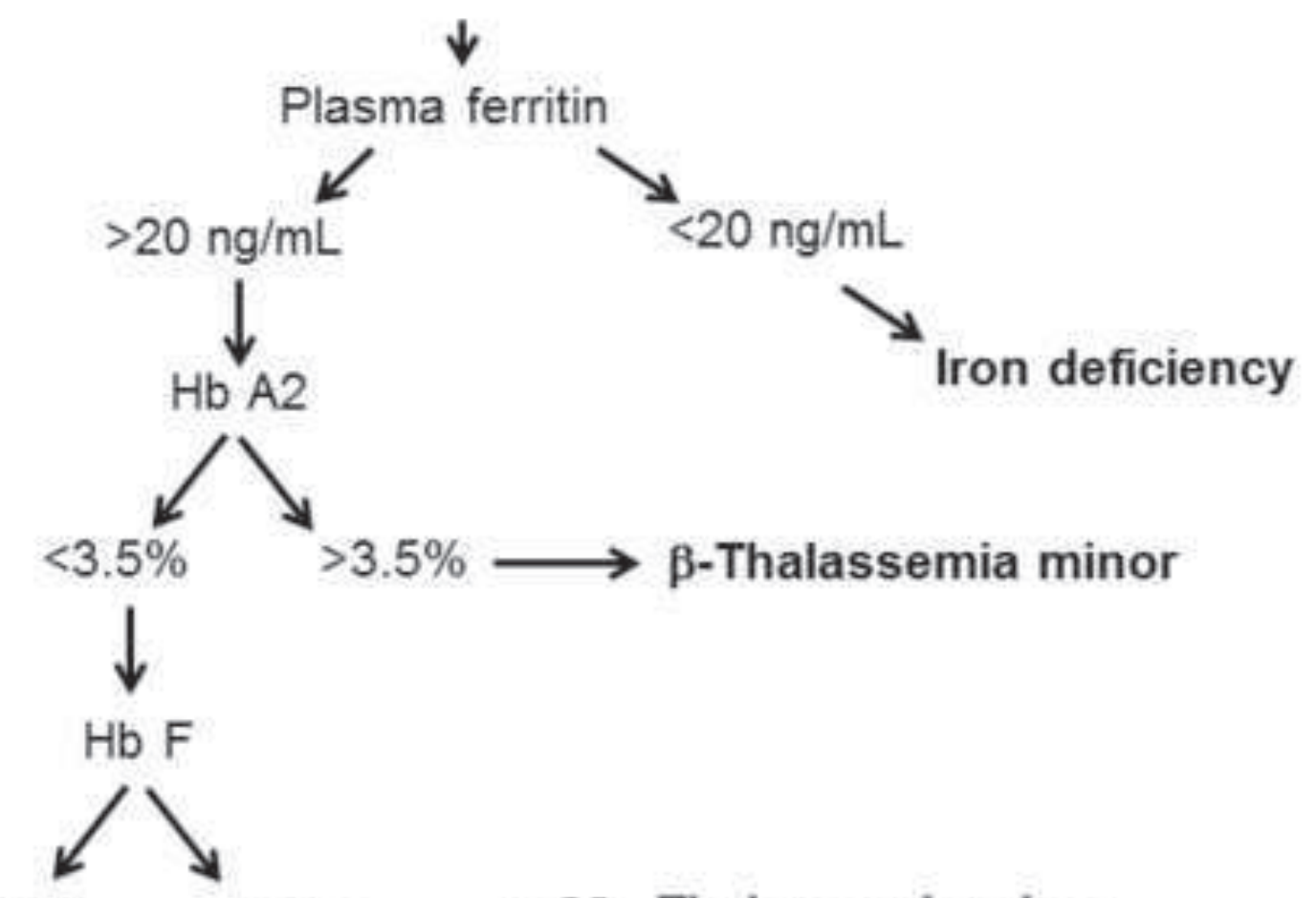

Normal Abnormal

electrophoresis electrophoresis $\longrightarrow \mathrm{Hb}$ Lepore, $\mathrm{HbH}$, etc.<smiles>C1C[Al]C1</smiles>

Clinical records

Compatible

diagnosis

$$
\downarrow
$$

Anemia of inflammation
$>3 \% \longrightarrow \delta \beta$-Thalassemia minor

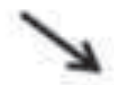

Normal

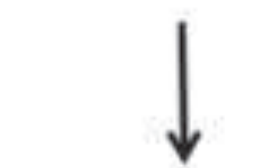

atypical

microcytosis 


\section{Figure 2}

A

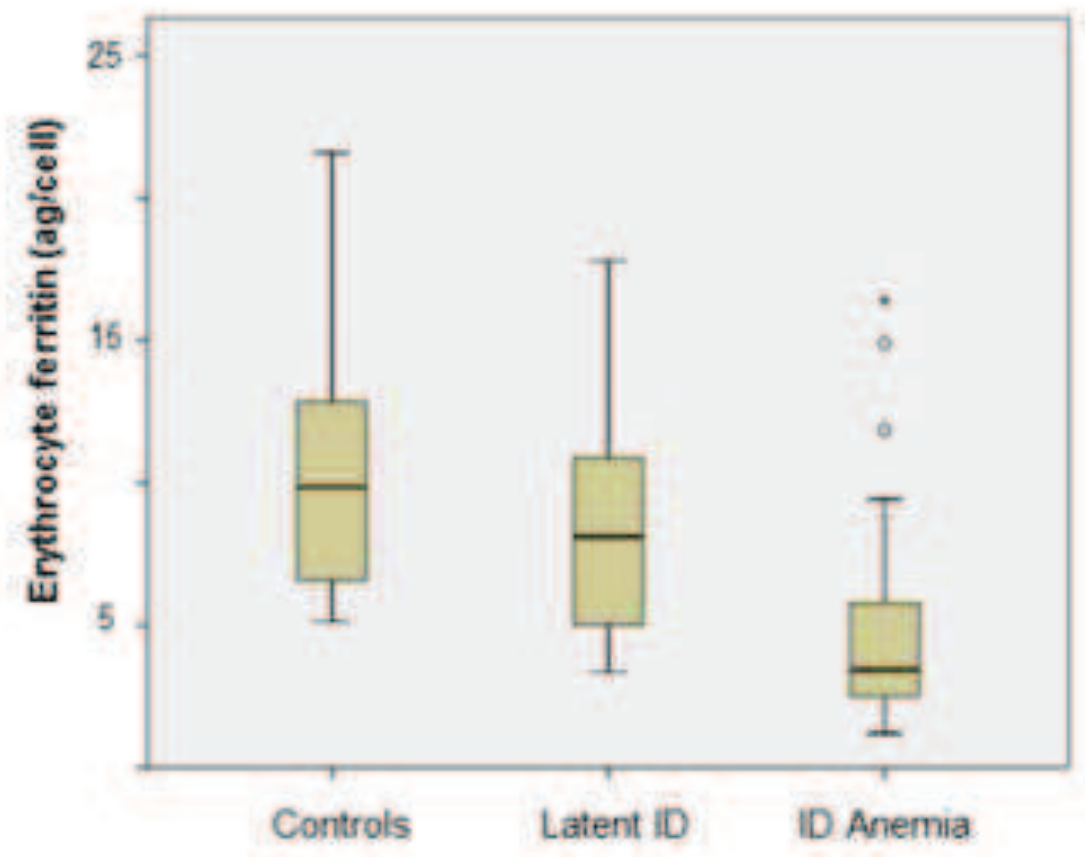

B

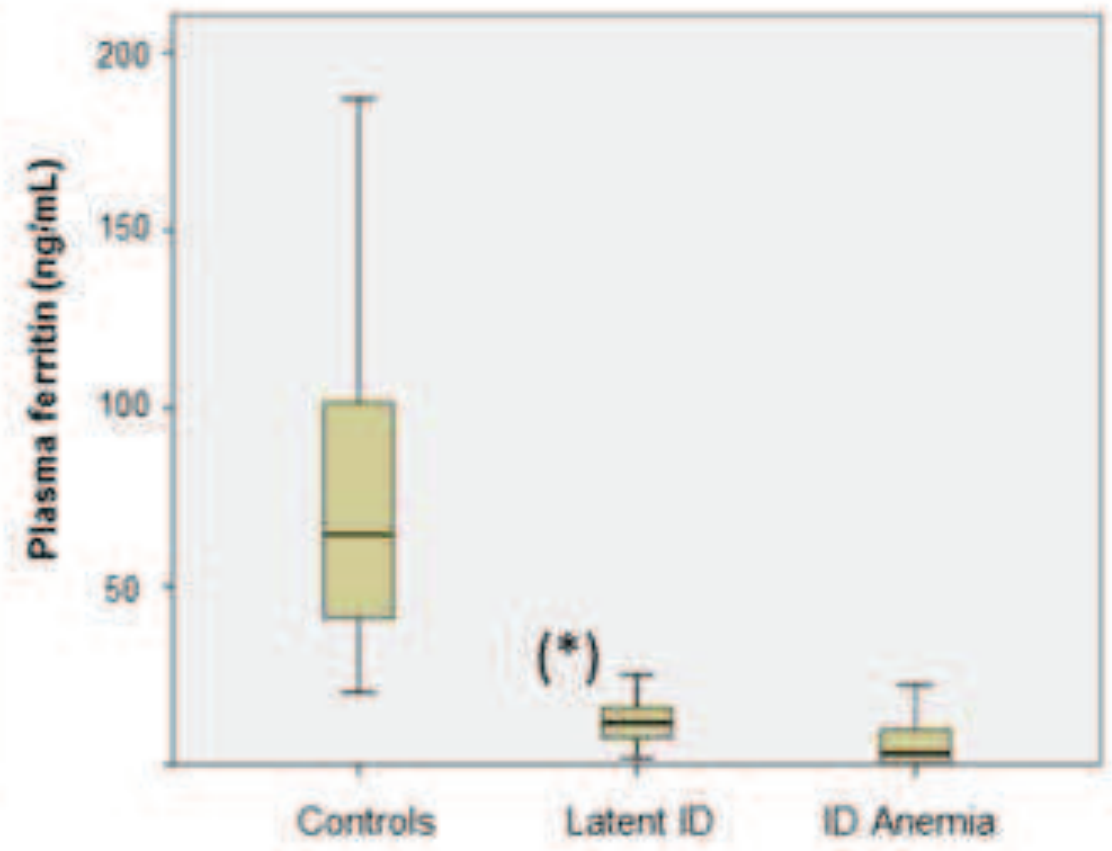




\section{Figure 3}
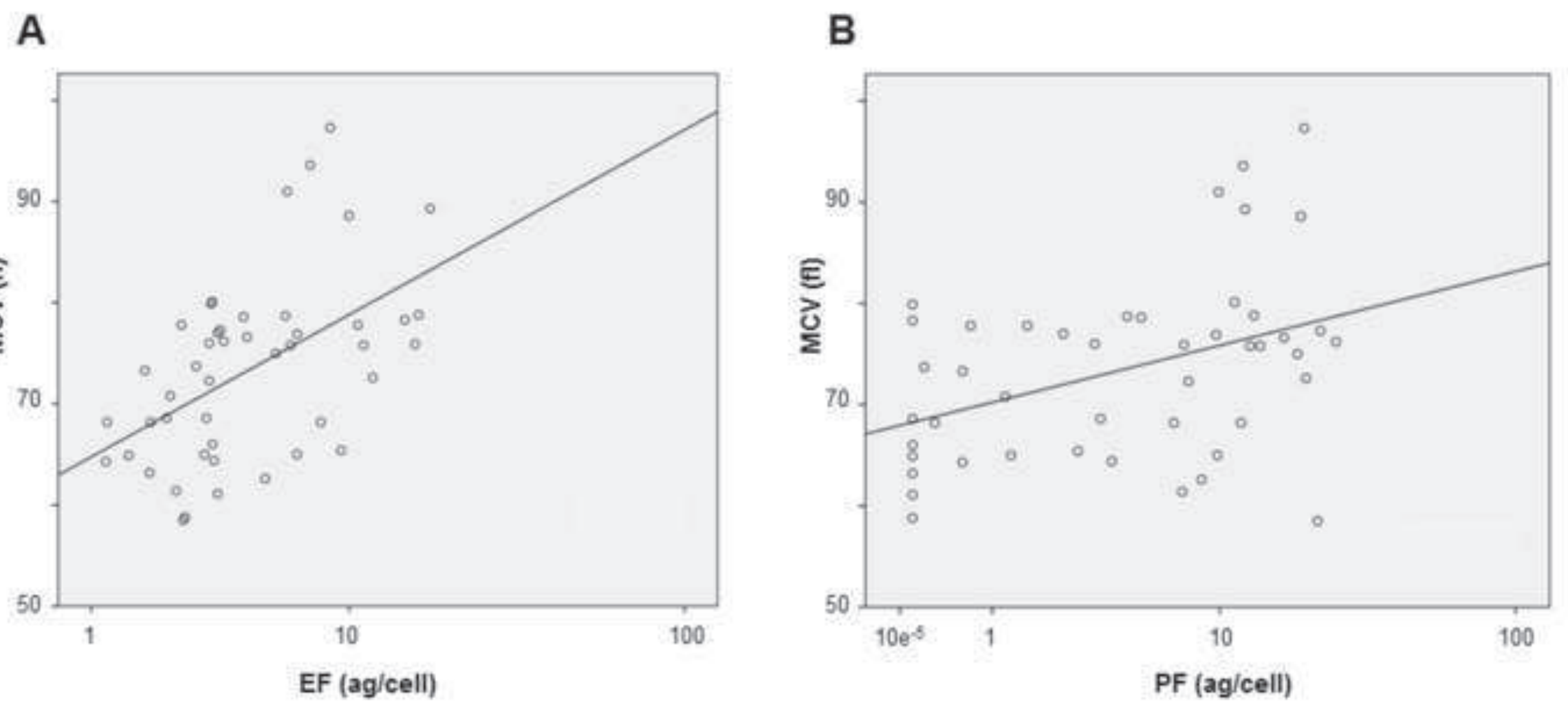


\section{Figure 4}

A

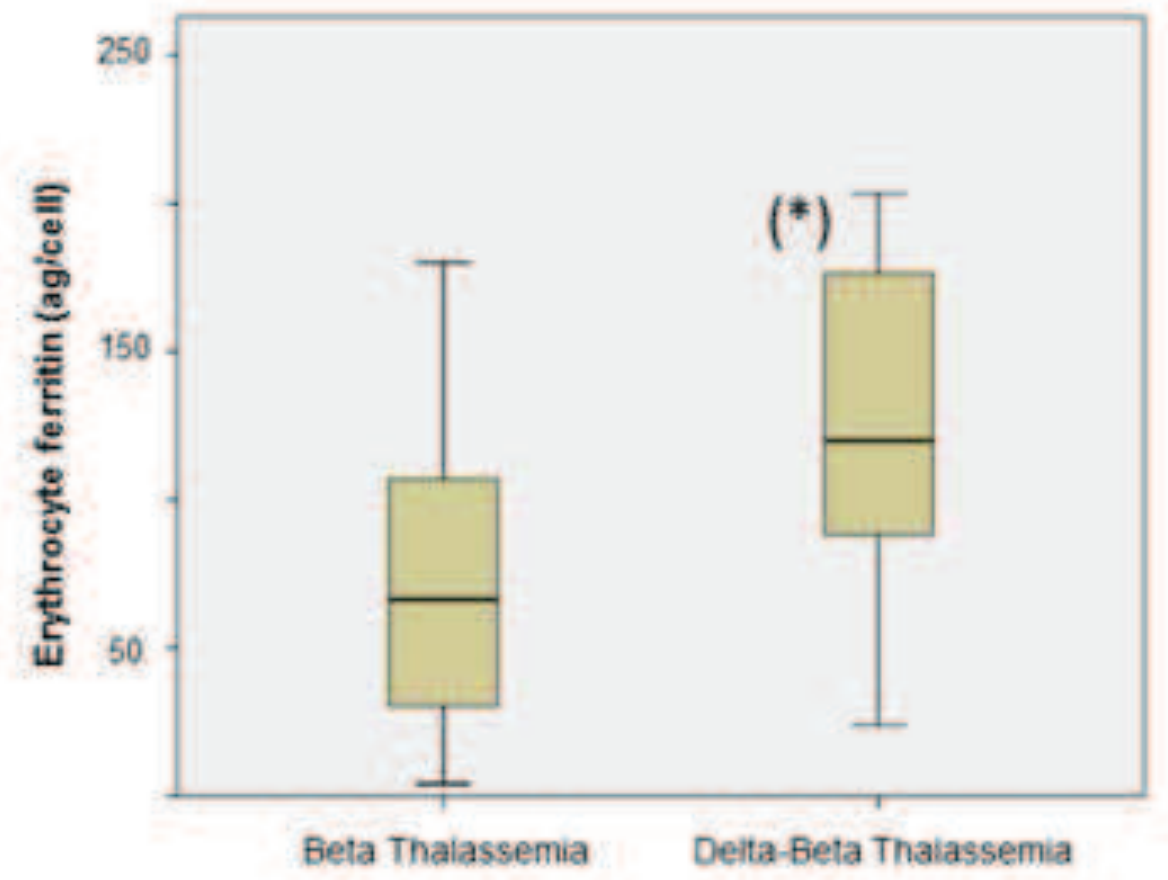

B

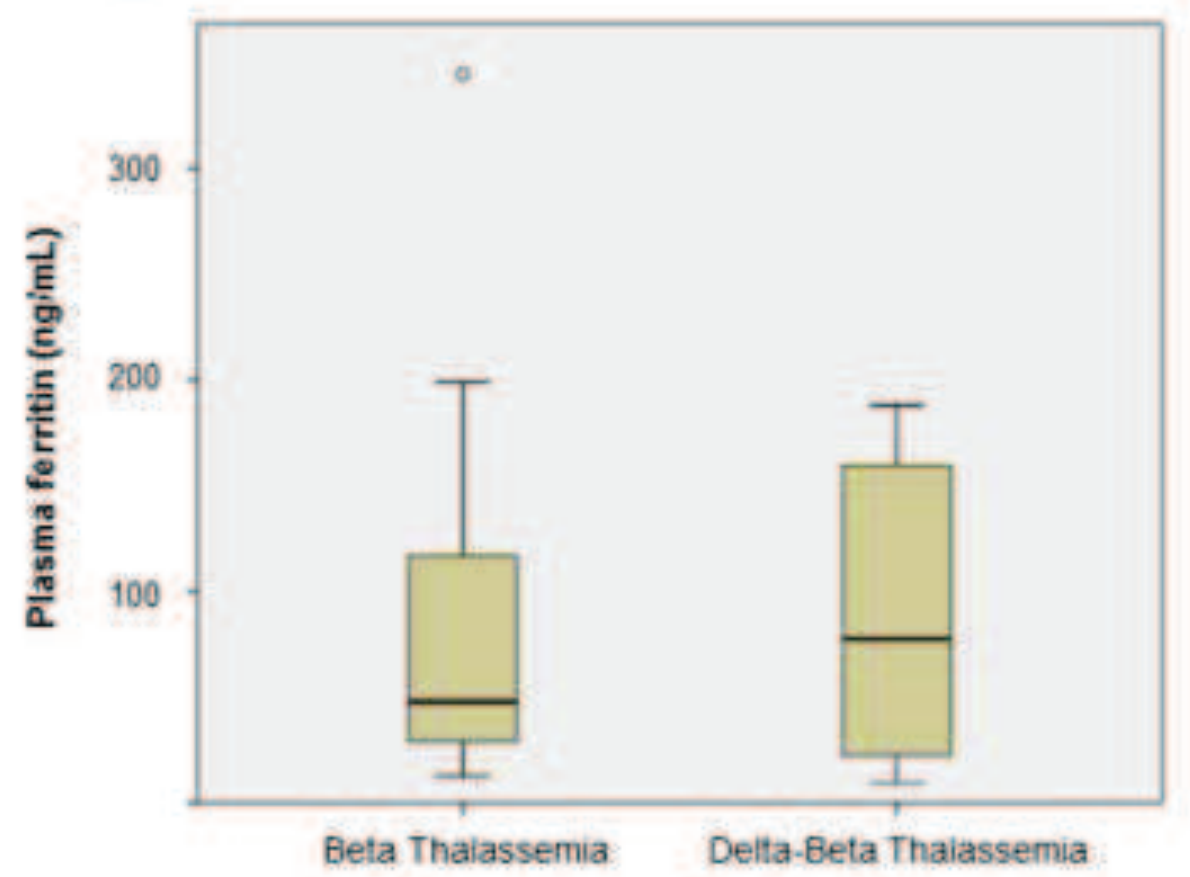




\section{Figure 5}

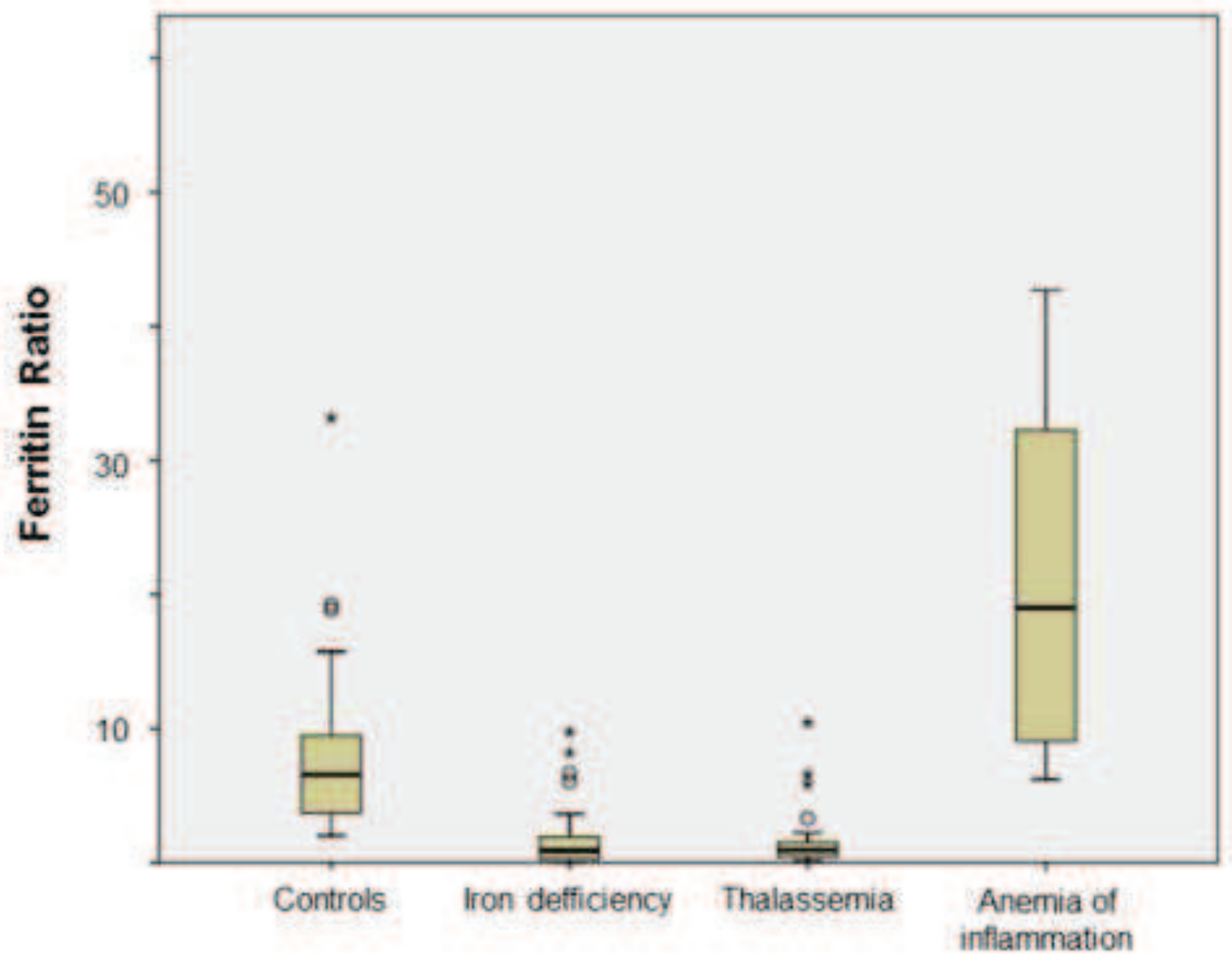

